\title{
Insumo e Autoria na Produção de Material Didático de Italiano como Língua de Herança
}

\author{
Tatiana Iegoroff de Mattos* \\ Fernanda Landucci Ortale \\ Rosângela Maria Laurindo Fornasier \\ Vinicio Corrias
}

RESUMO: Neste artigo relatamos o processo de produção de um material didático para o ensino de italiano como língua de herança que está sendo desenvolvido na comunidade de Pedrinhas Paulista, localizada no interior de São Paulo. Para isso, explicitamos as etapas de produção deste material e a configuração básica das unidades didáticas, dando uma dimensão de suas especificidades. Em seguida, levantamos algumas questões relativas aos insumos que têm sido utilizados na sua composição e o que precisa ser feito para garantir os seus direitos autorais. Em virtude disso, apresentamos os tipos de licenças que protegem os conteúdos que encontramos, principalmente daqueles retirados da internet. Nesta trajetória recorremos a autores que estudaram a produção de materiais didáticos, o ensino de italiano como língua de herança, e os insumos autênticos e suas precedências.

PALAVRAS-CHAVE: produção de material didático; italiano como língua de herança; direitos autorais; Pedrinhas Paulista.

ABSTRACT: In this article we report the didactic material for teaching italian as heritage language that is being developed in Pedrinhas Paulista, located in the countryside of São Paulo. For this, we explain the steps of production of this material and the basic configuration of the didactic units giving a dimension of it specificities. After this explanation, we raise some questions regarding the input that have been used in its composition and what is needed to make secure its copyrights. Because of this, we show the types of licences that protect the contents founded, mainly that withdrawn from internet. In this trajectory we resorted to authors that have studied didactic materials production, the teaching of italian as heritage language, and authentic input and their precedence.

KEYWORDS: didactic material production; italian as heritage language; copyright; Pedrinhas Paulista.

\footnotetext{
* Universidade de São Paulo, São Paulo (Brasil) — tatiana.mattos@usp.br / ortale@usp.br / rosangelamaria_romaria@yahoo.com.br / viniciocorrias@usp.br DOI: http://dx.doi.org/10.11606/issn.2238-8281.v0i36p47-57
} 
ABSTRACT: in questo articolo riportiamo il processo di produzione del materiale didattico per l'insegnamento dell' italiano come lingua di eredità che stiamo sviluppando nella comunità di Pedrinhas Paulista, situata nello stato di São Paulo. Per questo, spieghiamo le fasi di produzione di questo materiale e la configurazione base delle unità didattiche mostrando le sue specificità. Dopo questa presentazione, solleviamo alcune questioni riguardo gli input che sono stati utilizzati nella sua composizione e cosa si deve fare per proteggere $i$ diritti d'autore. Per questo motivo, presentiamo $i$ tipi di licenze che proteggono i contenuti che troviamo soprattutto su internet. In questo percorso abbiamo fatto ricorso a autori che hanno studiato la produzione di materiale didattico, l'insegnamento di italiano come lingua di eredità, e gli input autentici e la loro precedenza.

PAROLE-CHIAVE: la produzione di materiale didattico; l'italiano come lingua di eredità; diritti d'autore; Pedrinhas Paulista. 


\section{Introdução}

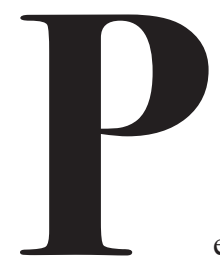

edrinhas Paulista localiza-se no interior do Estado de São Paulo e é uma ex-colônia italiana, fruto da última imigração italiana subsidiada para o Brasil. Foi fundada em 1952, elevada a Distrito em 1980 e em 1991 alcançou a emancipação político-administrativa. A cidade conta, atualmente, com uma população de cerca de 3.000 habitantes.

O projeto Italiano como Herança, implementado nessa cidade, visa à revitalização da língua italiana e de aspectos culturais junto à comunidade. Dentre os principais objetivos do projeto estão o oferecimento de um curso de italiano como língua de herança e a elaboração de um material didático para esse contexto. Tendo como pressuposto o fato de que os materiais para o ensino de língua estrangeira não são adequados para o ensino de língua de herança (LH), apontaremos algumas de suas especificidades.

A elaboração desse material ocorre de forma gradual, uma vez que a vivência dos alunos é importante para o andamento das aulas e o tema central de cada unidade é escolhido de acordo com o repertório de cada um e o que querem compartilhar em sala de aula. Isso permite, portanto, a elaboração de um material adequado às particularidades do contexto e, consequentemente, mais motivador para os discentes aos quais ele se destina.

Com base em estudiosos da área de ensino de língua de herança, Ortale, Fornasier e Corrias (2017) lembram que transpor características do ensino de qualquer língua estrangeira para um cenário de ensino de uma língua de herança não é adequado, pois o contexto de ensino de língua de herança exige especificidades quanto aos materiais didáticos, ferramentas de avaliação e formação de professores.

Devido às especificidades desse material e de todo o trabalho envolvido na produção de uma apostila adequada aos interesses próprios da comunidade, surgiu a necessidade, por parte dos autores, de registrar junto à Biblioteca Nacional aquilo que tem sido criado. Até o momento, existem três apostilas prontas e utilizadas no curso que vem sendo ministrado em Pedrinhas Paulista desde agosto de 2016, voltado principalmente para membros da primeira geração nascida no Brasil e seus cônjuges.

Neste artigo, portanto, mencionaremos a produção de um material didático para o ensino de italiano como língua de herança, que teve como principal matéria-prima as histórias de vida coletadas junto à comunidade antes do início do curso. Serão explicitadas a configuração do 
material, a aplicabilidade do mesmo em um curso e, por fim, as licenças que protegem os insumos utilizados e o que pode ser feito para viabilizar seu registro junto à Biblioteca Nacional.

\section{As histórias de vida como matéria-prima das atividades}

Antes de falarmos sobre o material produzido é importante lembrar que a não adoção de um livro didático e a opção pela elaboração de um material próprio deve-se, em grande medida, ao contexto em que se insere o projeto Italiano como Herança.

Muitos dos fundadores de Pedrinhas Paulista ainda encontram-se na cidade e carregam consigo boa parte da cultura que trouxeram da Itália. A língua italiana, no entanto, está se perdendo, uma vez que, morando no Brasil, as gerações que aqui nasceram foram priorizando o português nos contatos familiares e sociais.

Para quem mora em Pedrinhas Paulista, porém, não é como se o italiano fosse uma língua totalmente estrangeira: muitos cresceram ouvindo seus pais ou avós conversando entre si em italiano ou dialeto e mesmo aqueles que não são descendentes de italiano costumam ouvir tal idioma pelas ruas e praças da cidade, sem contar a presença de músicas italianas tocadas nas tradicionais festas italianas promovidas pela comunidade.

O que fomenta as discussões nas aulas, além das histórias de vida dos membros da comunidade, são cartas, poemas, textos de memórias, crônicas, notícias de jornal, vídeos da internet. Quando surge a necessidade de sistematizar algum conteúdo gramatical, também são utilizadas videoaulas disponíveis no youtube ou no curso online Dire, Fare, Partire!, desenvolvido na Universidade de São Paulo ${ }^{1}$.

Grande parte do material linguístico por nós utilizado foi elaborado junto à comunidade, como por exemplo, relatos pessoais escritos, entrevistas em vídeo - realizadas por membros do projeto antes do início do curso -, entrevistas feitas pessoalmente com membros da comunidade durante as aulas (...) (FORNASIER, 2018, p. 78).

As entrevistas realizadas com membros da própria comunidade abordam os seguintes temas: a saída da pátria, a chegada ao Brasil, a relação com as línguas, as diferenças culturais ou suas percepções identitárias. As gravações foram transcritas e didatizadas para o uso em sala.

A predileção pelo uso de materiais autênticos na composição das aulas dá-se pois, como afirma Tomlinson:

materiais autênticos podem fornecer uma exposição significativa à língua como ela é realmente utilizada, motivar os aprendizes e ajudá-los a desenvolver uma gama de competências comunicativas e promover uma atitude positiva em relação à aprendizagem de línguas. (TOMLINSON, 2012, p. 161).

1 Dire, Fare, Partire! é um conjunto de materiais didáticos gratuitos, elaborado especificamente para alunos e professores brasileiros de italiano, que pode ser utilizado como recurso para a autoaprendizagem, sem tutoria, ou em sala de aula presencial, com a mediação de um professor. Disponível em: < https://cursosextensao.usp.br/course/view. php?id=131>. 
O que mais motiva os alunos do curso de italiano são as entrevistas já mencionadas, sejam aquelas gravadas pelos pesquisadores antes do início do curso, sejam as que foram realizadas durante o horário das aulas, ao final de cada unidade didática. Isto se explica pelo fato de que as entrevistas trazem muito da história e da cultura de seus antepassados e também propiciam momentos de troca, em que os alunos conversam em italiano sobre aquilo que aprenderam e aquilo que já vivenciaram.

Todos estes elementos justificam o fato de que quando o curso foi iniciado, em agosto de 2016, apenas a primeira unidade estava totalmente pronta. Sendo a vivência dos alunos um elemento fundamental para a produção desse material didático, era preciso conhecê-los e ouvi-los, para que suas histórias pudessem ser compreendidas e inseridas como parte do curso.

À medida que as atividades eram aplicadas, observávamos como os alunos interagiam entre si e como reagiam diante da tarefa proposta, se foi uma experiência prazerosa, se tínhamos atingido os objetivos traçados para aquela aula (FORNASIER, 2018, p. 79).

Ao darmos espaço para que cada aluno contasse a sua história, acabamos despertando o interesse de outros membros da comunidade que prontamente quiseram ajudar, contribuindo com fotografias, documentos e cartas que, aos poucos, também foram sendo inseridos em nosso material didático. Esses membros vieram até nós por meio dos próprios alunos, ou então tiveram seu interesse despertado pela simples divulgação do curso, seja no período de matrícula, seja através da página deste no Facebook $^{2}$, que foi alimentada principalmente durante os dois primeiros módulos do curso.

\section{A organização das unidades e os resultados positivos do material}

Todas as unidades didáticas elaboradas para o material utilizado no curso de Italiano como Herança possuem uma estrutura mais ou menos semelhante: o tema é apresentado por meio de algumas imagens; em seguida, faz-se a leitura de um texto introdutório, sempre em italiano, ao qual se seguem as atividades orais e as atividades escritas. Por fim, todas as unidades contam com uma música, que geralmente se relaciona com o tema tratado. Quando se faz necessário o esclarecimento de algum ponto gramatical, ele sempre vem exposto antes da canção.

Cada uma das apostilas do curso conta com quatro unidades didáticas e optou-se por uma estruturação em tópicos de conteúdo e não com base em uma progressão de itens gramaticais:

Num contexto de LH observa-se, então, que o ensino da língua requer uma abordagem de ensino específica, bem como um material didático diferenciado, uma vez que ensinar uma língua de herança vai além do ensino estrutural da língua, requer a compreensão dessa cultura, tendo em vista que ela contribui para a construção da identidade desse aluno (FORNASIER, 2018, p. 67).

2 Para conhecer a página, basta acessar: $<$ https://www.facebook.com/italianocomoheranca/>. 
Os assuntos trabalhados nas três primeiras apostilas foram:

Tab. 1 - Apostila

\begin{tabular}{|c|c|c|c|c|}
\hline Apostila & Unidade 1 & Unidade 2 & Unidade 3 & Unidade 4 \\
\hline 1 & $\begin{array}{c}\text { Imigração italiana } \\
\text { no mundo }\end{array}$ & $\begin{array}{c}\text { Imigração italiana } \\
\text { atual }\end{array}$ & Culinária italiana & $\begin{array}{c}\text { História da língua } \\
\text { italiana }\end{array}$ \\
\hline 2 & $\begin{array}{c}\text { História e impor- } \\
\text { tância dos dialetos }\end{array}$ & $\begin{array}{c}\text { Segunda Guerra } \\
\text { Mundial }\end{array}$ & $\begin{array}{c}\text { Pároco Ernesto } \\
\text { Montagner }\end{array}$ & Choque cultural \\
\hline 3 & Música italiana & $\begin{array}{c}\text { História da Com- } \\
\text { panhia Brasileira } \\
\text { de Colonização }\end{array}$ & $\begin{array}{c}\text { Cooperativa } \\
\text { Agropecuária de } \\
\text { Pedrinhas Paulista }\end{array}$ & $\begin{array}{c}\text { O jardim de infância } \\
\text { fundado por Dom } \\
\text { Ernesto Montagner }\end{array}$ \\
\hline
\end{tabular}

Outra característica importante é o fato de que as apostilas foram elaboradas por mais de uma pessoa: a professora do curso e suas duas colaboradoras, um doutorando, uma graduanda e a professora-coordenadora do projeto.

Cada um desses elaboradores procurou seguir a estrutura básica das unidades, além de apoiarem-se nas fases de desenvolvimento de materiais didáticos propostas por Vilson Leffa (2007). Segundo o autor, a produção de um material didático deve passar por quatro etapas: análise, desenvolvimento, implementação e avaliação.

Antes de adentrar cada uma dessas etapas era preciso, no entanto, compreender o que significa didatizar um material autêntico. Para Vieira (2012) a didatização

designa o complexo processo de exploração do texto autêntico por meio de técnicas didáticas que visam torná-lo acessível e compreensível aos alunos, fazendo com que este seja realmente um instrumento de ensino-aprendizagem da língua-alvo (VIEIRA, 2012, p. 68).

Compreendemos que o processo de didatização é complexo por implicar a escolha de materiais adequados às necessidades dos alunos e que seja do interesse deles; por ser necessário definir e delimitar objetivos a serem atingidos; por tornar crucial a elaboração de atividades que explorem o material selecionado, de forma a concretizar os objetivos estipulados anteriormente. 
Retomando, então, as etapas propostas por Leffa (2007), a análise consiste em conhecer os alunos, seus gostos e suas necessidades. Para isso, no ato de inscrição no curso de Italiano como Herança os alunos preencheram um formulário em que deveriam explicitar se eram descendentes de italianos ou não, a região de origem da família e conhecimento da língua italiana e a relação com o dialeto familiar.

Já o desenvolvimento é a parte principal de todo o processo, sendo necessário definir os objetivos, a abordagem, o conteúdo, as atividades e os recursos. O objetivo do curso é a revitalização da língua e da cultura dos imigrantes que fundaram a cidade; a abordagem adotada foi a baseada em conteúdo (LEFFA, 2007, p. 26), em que buscamos priorizar os insumos autênticos, para propor atividades de fala, escuta, leitura e escrita. Com relação às apostilas, optamos por entregar uma cópia impressa a cada aluno, sem deixar de lado, em sala de aula, o uso de recursos tecnológicos de projeção e acesso à internet.

A fase seguinte é a da implementação, que pode variar conforme a maior ou menor presença de quem preparou o material na hora de efetivamente utilizá-lo. No caso do material que estamos analisando, a professora e duas pessoas que colaboram com ela em sala de aula são, também, grandes responsáveis pela produção do material didático. A maioria das unidades foram elaboradas por elas e aquelas que não foram, passaram por sua análise. A escolha dos temas parte de todos os integrantes do projeto.

Por fim, chegamos à avaliação: o material utilizado em Pedrinhas Paulista é constantemente submetido a este processo. A professora e suas colaboradoras avaliam aula a aula as atividades realizadas e discutem o que poderia ser modificado. Nos casos em que as unidades são produzidas por outros membros do projeto Italiano como Herança podem existir, ainda, questionários respondidos por alunos e professores para saber a opinião de todos os envolvidos na utilização do material.

Grande parte dos comentários dos alunos é positiva, seja nos questionários aplicados, seja pessoalmente, ao final da aula: para eles as atividades costumam ser motivantes, divertidas e despertam emoções, uma vez que os faz relembrar e conhecer sua própria história. Nos casos em que os comentários revelaram a percepção de que as atividades foram cansativas ou os temas desinteressantes, as professoras procuraram trabalhar na melhoria do material apresentado para evitar que a situação se repetisse.

\section{Os insumos e a questão do registro do material}

Encontrar materiais dos mais diversos tipos na internet não é uma tarefa difícil, bem como utilizá-los em sala de aula. No entanto, inserir esses insumos em uma apostila requer alguns cuidados, principalmente se quisermos registrar aquilo que for produzido.

O principal empecilho encontrado é o fato de que a maioria dos materiais que encontramos na internet - como vídeos, imagens e textos - são protegidos por copyright, ou seja, somente o autor compositor ou editor pode imprimir, reproduzir e/ou vender a obra por ele produzida. 
Alguns insumos, porém, são protegidos por outros tipos de licenças, como o Creative Common que, de acordo com Souza, "consiste em um sistema de licenciamento em que o artista ou autor define quais direitos e liberdades serão atribuídas à sua produção" (SOUZA, 2016, p. 34) e o Domínio Público, em que não há direitos reservados ao autor/produtor da obra.

Ao produzirmos um material didático em que são utilizados alguns conteúdos elaborados por terceiros, deveríamos, portanto, selecionar aqueles licenciados através de Creative Commons ou Domínio Público. Em casos de materiais protegidos por Copyright seria preciso entrar em contato com o proprietário da obra para resolver a questão dos direitos autorais.

Em seu trabalho, Souza (2016) menciona os seis tipos de licenças que existem no Creative Commons: Atribuição (CC BY), Atribuição Não Comercial (CC BY-NC), Atribuição Compartilha Igual (CC BY-SA), Atribuição Sem Derivados (CC BY-ND), Atribuição Não Comercial Compartilha Igual (CC BY-NC-SA) e, por fim, Atribuição Não Comercial Sem Derivados (CC BY-NC-ND). Cada uma dessas licenças é representada por um símbolo diferente, como podemos ver na tabela a seguir:

Tab. 2 - Licenças

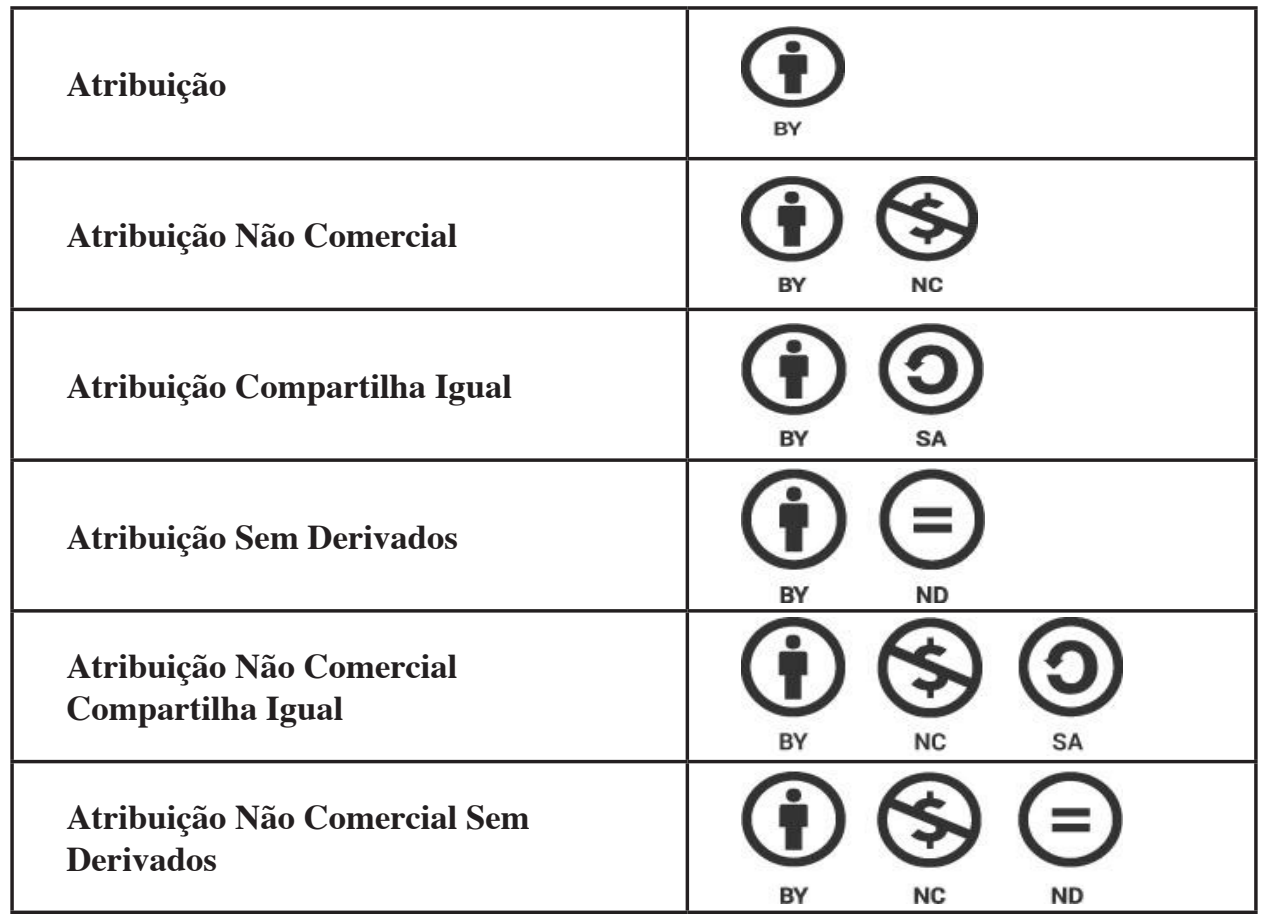

fonte: adaptado de Creative Commons Brasil 
Quando uma obra está licenciada somente por Atribuição significa que outras pessoas podem distribuí-la, adaptá-la e até mesmo modificá-la, desde que sejam dados os créditos pela criação original. Com a Atribuição Não Comercial o que muda em relação à primeira é que a obra derivada deve ser produzida para fins não comerciais. Para obras com Atribuição Compartilha Igual, pode haver distribuição comercial desde que os créditos sejam atribuídos e que a obra derivada seja licenciada da mesma forma. A Atribuição Não Comercial Compartilha Igual une as duas últimas licenças, ou seja, pode-se trabalhar sobre a obra original de maneira não comercial e compartilhando com a mesma licença. Atribuição Sem Derivados não permite que a obra original seja modificada, mas permite sua redistribuição de maneira comercial ou não, com a presença dos créditos. No caso da Atribuição Não Comercial Sem Derivados a obra original pode ser compartilhada desde que não sofra alteração alguma e apenas de maneira não comercial, o que torna sua inserção em um livro didático a ser vendido comercialmente impossível.

No caso do material didático elaborado para o curso de Italiano como Herança ministrado em Pedrinhas Paulista, não há pretensões de usá-lo de forma comercial, justamente por fazer parte de um projeto cultural e histórico amplo. Ainda assim, analisando o material percebemos que há muitos elementos que impediriam seu registro junto à Biblioteca Nacional. É o caso das imagens utilizadas no início de cada unidade, além de certas reportagens e textos.

Algumas soluções encontradas para o nosso problema são bem simples: optamos por substituir as imagens retiradas da internet por imagens feitas pelos próprios colaboradores, preferencialmente de paisagens ou objetos, pois a presença de pessoas na foto implica a autorização delas também para o uso da mesma. Com relação aos textos, conforme a comunidade vai disponibilizando materiais - como relatos pessoais, cartas de família, documentos - , pode-se pedir autorização de uso para colocá-los em substituição aos textos selecionados anteriormente.

As entrevistas que gravamos para o projeto foram feitas mediante a assinatura de um termo de consentimento de uso da imagem para fins não comerciais. Além disso, os demais materiais disponibilizados pelos alunos e pela comunidade são inseridos no material apenas com autorização escrita por parte do autor. Para preservar a identidade dos membros da comunidade que assim preferirem, seus nomes são substituídos por nomes fictícios e evita-se a inserção de trechos extremamente pessoais.

Produzir um material para o ensino de línguas de herança possui, portanto, esta vantagem: ao tentar reconstruir a história e os costumes de uma comunidade temos acesso aos produtores ou detentores do material necessário a isso, ou seja, os próprios habitantes da cidade.

\section{Conclusão}

A elaboração de um material didático requer tempo, conhecimento e criatividade. Encontrar textos teóricos sobre o tema não é muito difícil, mas em relação à elaboração de materiais didáticos para o ensino de línguas de herança, a bibliografia é muito menos extensa. $\mathrm{O}$ trabalho 
que vem sendo realizado na cidade de Pedrinhas Paulista, por meio do projeto Italiano como Herança, portanto, precisa ser divulgado, uma vez que pode contribuir para outras colônias e núcleos de imigrantes que existem no Brasil.

Existem diversas formas de viabilizar essa divulgação: por meio das pesquisas científicas, de artigos científicos sobre o assunto e com o registro do próprio material didático junto à Biblioteca Nacional.

Este registro é importante, também, para preservar a originalidade do trabalho, em que não há finalidade comercial para o material didático, que integra um projeto que é fruto de colaborações entre a Universidade de São Paulo e a comunidade de Pedrinhas Paulista. Mesmo assim, é preciso seguir algumas normas com relação àquilo que é reproduzido nas páginas das apostilas e, por isso, algumas alterações fazem-se necessárias.

Neste artigo buscamos apresentar o curso de Italiano como Herança que vem sendo ministrado em Pedrinhas Paulista, dando maior destaque ao material didático. Para isso, foi preciso tratar da importância das histórias de vida e do papel da comunidade para a composição do material, da maneira que esse material está estruturalmente organizado e quais teorias foram seguidas em sua elaboração. Também ressaltamos algumas reflexões acerca daquilo que já foi aplicado em sala de aula, além de fazer uma breve análise da procedência dos insumos utilizados e como tornar este material mais efetivo e passível de um registro junto à Biblioteca Nacional.

\section{Referências}

CREATIVE COMMONS BRASIL. "Licenças". Disponível em: <https://br.creativecommons.org/ licencas/>. Acesso: 03/05/2018.

FORNASIER, R. M. L. A produção de material didático para o ensino de italiano como língua de herança na perspectiva pós-método. Dissertação (Mestrado em Língua e Literatura Italiana). São Paulo: Faculdade de Filosofia, Letras e Ciências Humanas da Universidade de São Paulo, 2018.

LEFFA, V. J. Como produzir materiais para o ensino de línguas. In: LEFFA, V. J. (org.) Produção de materiais de ensino: Teoria e prática. Pelotas: Educat, 2007, p. 15-41.

ORTALE, F.L.; CORRIAS, V.; FORNASIER, R.M.L. Desafios no ensino da língua de herança: o italiano em Pedrinhas Paulista. In Revista Letras Raras, Campina Grande: v. 6, (n. 2): 72-86, 2017.

SOUZA, R. F. Implicações do uso de material didático livre em contexto formal de ensino-aprendizagem de italiano como LE/L2: A perspectiva dos problemas de ensino. Tese (Doutorado em Língua e Literatura Italiana). São Paulo: Faculdade de Filosofia, Letras e Ciências Humanas da Universidade de São Paulo, 2016.

TOMLINSON, B. Materials development for language learning and teaching. Language Teaching. In Language Teaching. Cambridge: v.45: 2012. Disponivel em: <https://www.cambridge.org/core/journals/ language-teaching/article/materials-development-for-language-learning-and-teaching/AB9B247D6CDA981F0E3BDCD8FC3DBE36>. Acesso: 06/04/2018.

VIEIRA, D. A. A didatização de materiais autênticos para o ensino do italiano como língua estrangeira. Dissertação (Mestrado em Língua e Literatura Italiana). São Paulo: Faculdade de Filosofia, Letras 
e Ciências Humanas da Universidade de São Paulo, 2012.

Recebido em: 12/06/2018

Aprovado em: 31/10/2018 